\title{
UDC 519.615
}

\section{MODELING TIME SERIES OF ATM LOCAL VOLATILITY FOR MICROSOFT STOCKS}

Bondarenko M.V. / Бондаренко M.B.

Ph.D. student / аспіранm

ORCID: 0000-0002-4792-6420

Master's Degree in Quantitative Finance and Risk Management

Consultant Developer C++, CapFi Groupe, France

Bondarenko V.M. / Бондаренко В.М.

c.t.s., as.prof. / к.m.н., доч.

ORCID: 0000-0003-1663-4799

National Technical University of Ukraine «Igor Sikorsky Kyiv Polytechnic Institute», Kyiv, prosp. Peremogy, 37, 03056 Національний технічний університет Украйни «Кийвсъкий політехнічний інститут імені Ігоря Сікорського», Киӥв,, просп. Перемоги, 37, 03056

\begin{abstract}
In this work we apply simple linear and polynomial regression to model the time series of at-the-money (ATM) local volatility of Microsoft stocks and predict its out-of-sample values. Multiple researches consider ATM local volatility to be a good measure of the expected variance of the stock so predicting such measure allows trader to use successfully different option strategies and gain profit by trading volatility options.

We assumed that Microsoft stock price follows Dupire local volatility process and applied genetic algorithm of optimization to calibrate local volatility matrix from the set of Microsoft option prices. We repeated this procedure on multiple calibration dates and obtained a vector of ATM only values (at different calibration dates) per maturity. We applied linear regression to model these time series.

Model validation is done on a cross-validation dataset and a predictive dataset. We chose MSE (mean squared error) to be a measure of quality of the prediction. We also measure the statistical significance and predictive ability of such model and study autocorrelation tendencies.

ANOVA suggests that assumptions to use linear regression are held. No autocorrelation tendencies were discovered in the time series. Finally we conclude that neither $1^{\text {st }}$ nor $3^{\text {rd }}$ order linear regression has a predictive ability over out-of-sample local volatility despite $3^{\text {rd }}$ order model fits the data much better for different datasets. Moreover there is no linear relationship between correlation date and local volatility so such models are statistically insignificant and can't be used to forecast local volatility values.
\end{abstract}

Keywords: Local volatility, Dupire local volatility process, genetic algorithm, autocorrelation, polynomial regression, genetic algorithm, statistical significance, forecast.

Local volatility matrix is calibrated from prices of Vanilla options (Calland Put) available in the market. We want to calibrate such matrix at different dates in the past. We call these dates "calibration dates". It's done to be able to model the time series of the local volatility and predict its out-of-sample (OOS) values.

Each vanilla option is characterized by its maturity and strike price and for each such option the local volatility is calibrated by assuming that its underlying asset's price follows Dupire model [1].

$$
d S_{t}=S_{t}\left(\mu d t+\sigma\left(S_{t}, t\right) d W_{t}\right)
$$

That's why this volatility is called local as it has unique value for each maturity and strike. In simpler Black Sholes model it's a unique scalar independent of the maturity at given strike [2]. 
Input data is a set of prices of Vanilla options on MSFT stocks from NASDAQ. Option prices are available for multiple trading dates between January and April 2020. The period is also interesting as there were huge jumps of volatility. As input data is sparse and maturities/strikes differ between calibration dates we use linear interpolation on maturity axis to obtain the same grid for each of calibration dates and fill missing values. The grid is represented by these fractions of the year:

Maturities grid $(N=6)$ : $[0.05,0.1,0.15,0.2,0.25,0.4]$

Given $\mathrm{N}$ - number of maturities and $\mathrm{M}$ - number of strikes we firstly calibrate N X M matrix (ex. Fig.1) from the set of options for each of $\mathrm{K}$ calibration dates using genetic algorithm of optimization of Cerf [5] to handle the ill-posed character of the problem [3]. To improve the convergence of the algorithm we use adaptive weight coefficients to give more significance to near-the-money and at-the-money (ATM) values (i.e. local volatility corresponding to options whose strike is close or equals to the spot price of the underlying asset) [4]. Hence we obtain $\mathrm{K}$ matrices of $N X M$ dimensionality similar to one on Fig.1.

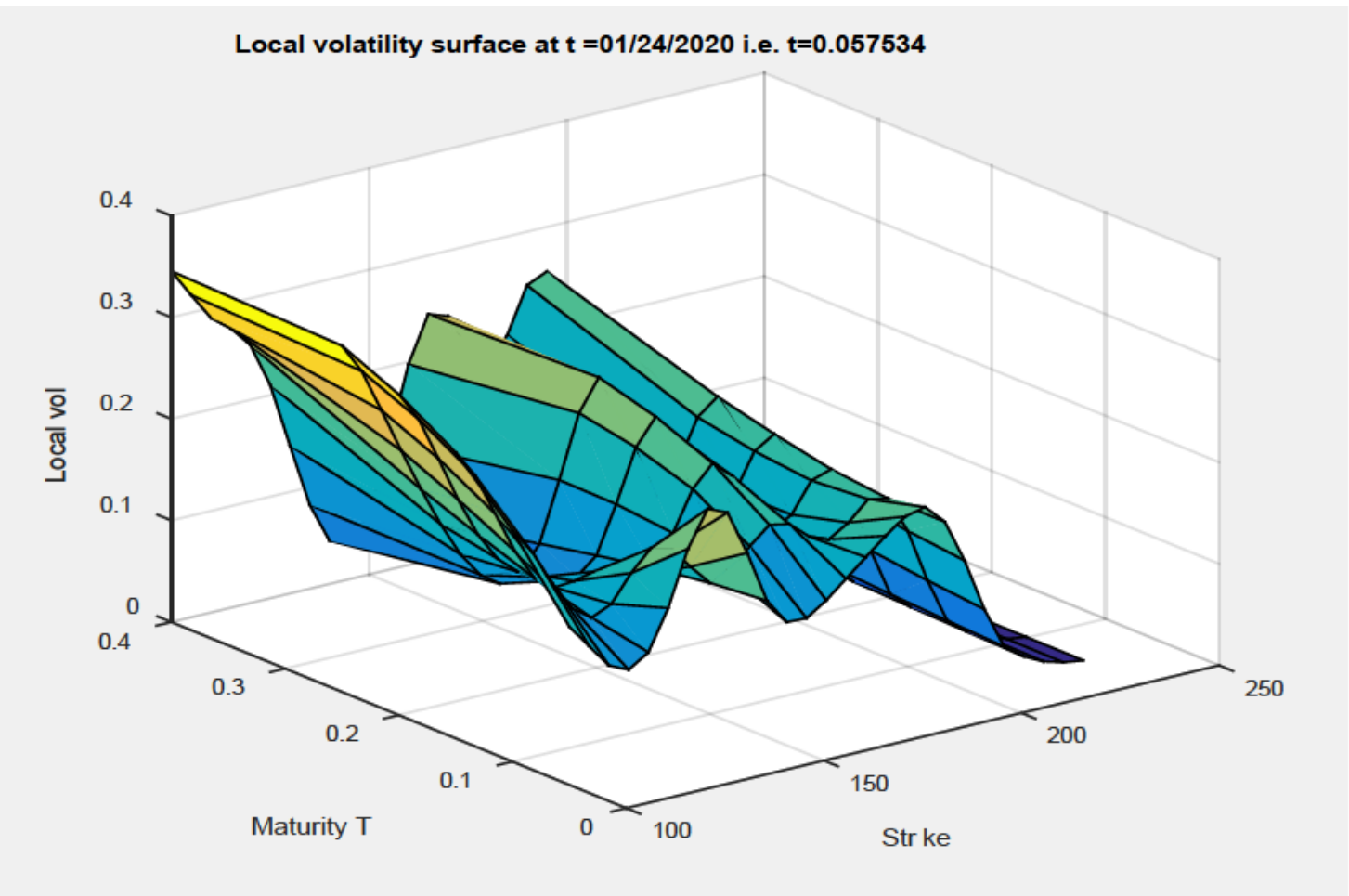

Fig.1. Local volatility matrix calibrated at $t=01 / 24 / 2020$

Multiple researches consider ATM local volatility to be a good measure of the expected variance of the stock [6] so predicting such measure allows trader to use successfully different option strategies and gain profit by trading volatility options. Therefore because of its practical significance but also to reduce the dimensionality of the problem we extract only ATM local volatilities. Thus we get rid of strike axis and obtain $N X K$ matrix of local volatilities. Basically we obtain the term structure of ATM local volatility for each maturity (ex. For maturity $T=0.05$ is on Fig.3). 
Our term structure corresponds to calibration dates from Table 1 and Table 2.

Table 1

Cross validation dataset

\begin{tabular}{|c|c|c|c|c|c|c|c|c|}
\hline $\begin{array}{l}\text { Calibration } \\
\text { Dates }\end{array}$ & $\begin{array}{l}01 / 03 / \\
2020\end{array}$ & $\begin{array}{l}01 / 10 / \\
2020\end{array}$ & & $\begin{array}{l}01 / 24 / \\
2020\end{array}$ & $\begin{array}{l}01 / 31 / \\
2020\end{array}$ & $\begin{array}{l}02 / 07 / \\
2020\end{array}$ & & \\
\hline $\begin{array}{l}\text { Validation } \\
\text { dates } \\
\text { (OOS) }\end{array}$ & & & $\begin{array}{l}01 / 17 / \\
2020\end{array}$ & & & & $\begin{array}{l}02 / 14 / \\
2020\end{array}$ & $\begin{array}{l}02 / 21 / \\
2020\end{array}$ \\
\hline Spot MSFT & $\begin{array}{l}158.62 \\
00\end{array}$ & $\begin{array}{l}161.34 \\
00\end{array}$ & $\begin{array}{l}167.10 \\
00 \\
\end{array}$ & $\begin{array}{l}165.04 \\
00\end{array}$ & $\begin{array}{l}170.23 \\
00\end{array}$ & $\begin{array}{l}183.89 \\
00\end{array}$ & $\begin{array}{l}185.35 \\
00\end{array}$ & $\begin{array}{l}178.59 \\
00 \\
\end{array}$ \\
\hline $\begin{array}{l}\text { Calibration } \\
\text { Dates }\end{array}$ & $\begin{array}{l}02 / 28 / \\
2020\end{array}$ & $\begin{array}{l}03 / 06 / \\
2020\end{array}$ & & $\begin{array}{l}03 / 20 / \\
2020\end{array}$ & $\begin{array}{l}03 / 27 / \\
2020\end{array}$ & $\begin{array}{l}04 / 03 / \\
2020\end{array}$ & & \\
\hline $\begin{array}{l}\text { Validation } \\
\text { dates } \\
\text { (OOS) }\end{array}$ & & & $\begin{array}{l}03 / 13 / \\
2020\end{array}$ & & & & $\begin{array}{l}04 / 09 / \\
2020\end{array}$ & $\begin{array}{l}04 / 17 / \\
2020\end{array}$ \\
\hline Spot MSFT & $\begin{array}{l}162.01 \\
00\end{array}$ & $\begin{array}{l}161.57 \\
00\end{array}$ & $\begin{array}{l}158.83 \\
00\end{array}$ & $\begin{array}{l}137.35 \\
00\end{array}$ & $\begin{array}{l}149.70 \\
00\end{array}$ & $\begin{array}{l}153.83 \\
00\end{array}$ & $\begin{array}{l}165.14 \\
00\end{array}$ & $\begin{array}{l}178.60 \\
00\end{array}$ \\
\hline
\end{tabular}

Table 2

Predictive validation dataset

\begin{tabular}{|l|l|l|l|l|l|l|l|l|}
\hline $\begin{array}{l}\text { Calibration } \\
\text { Dates }\end{array}$ & $\begin{array}{l}01 / 03 / \\
2020\end{array}$ & $\begin{array}{l}01 / 10 / \\
2020\end{array}$ & $\begin{array}{l}01 / 17 / \\
2020\end{array}$ & $\begin{array}{l}01 / 24 / \\
2020\end{array}$ & $\begin{array}{l}01 / 31 / \\
2020\end{array}$ & $\begin{array}{l}02 / 07 / \\
2020\end{array}$ & $\begin{array}{l}02 / 14 / \\
2020\end{array}$ & $\begin{array}{l}02 / 21 / \\
2020\end{array}$ \\
\hline $\begin{array}{l}\text { Validation } \\
\text { dates } \\
\text { (OOS) }\end{array}$ & & & & & & & & \\
\hline Spot MSFT & 158.62 \\
00 & $\begin{array}{l}161.34 \\
00\end{array}$ & $\begin{array}{l}167.10 \\
00\end{array}$ & $\begin{array}{l}165.04 \\
00\end{array}$ & $\begin{array}{l}170.23 \\
00\end{array}$ & $\begin{array}{l}183.89 \\
00\end{array}$ & $\begin{array}{l}185.35 \\
00\end{array}$ & $\begin{array}{l}178.59 \\
00\end{array}$ \\
\hline
\end{tabular}

\begin{tabular}{|c|c|c|c|c|c|c|c|c|}
\hline $\begin{array}{l}\text { Calibration } \\
\text { Dates }\end{array}$ & $\begin{array}{l}02 / 28 / \\
2020\end{array}$ & $\begin{array}{l}03 / 06 / \\
2020\end{array}$ & & & & & & \\
\hline $\begin{array}{l}\text { Validation } \\
\text { dates } \\
\text { (OOS) }\end{array}$ & & & $\begin{array}{l}03 / 13 / \\
2020\end{array}$ & $\begin{array}{l}03 / 20 / \\
2020\end{array}$ & $\begin{array}{l}03 / 27 / \\
2020\end{array}$ & $\begin{array}{l}04 / 03 / \\
2020\end{array}$ & $\begin{array}{l}04 / 09 / \\
2020\end{array}$ & $\begin{array}{l}04 / 17 / \\
2020\end{array}$ \\
\hline Spot MSFT & $\begin{array}{l}162.01 \\
00\end{array}$ & $\begin{array}{l}161.57 \\
00\end{array}$ & $\begin{array}{l}158.83 \\
00\end{array}$ & $\begin{array}{l}137.35 \\
00\end{array}$ & $\begin{array}{l}149.70 \\
00\end{array}$ & $\begin{array}{l}153.83 \\
00\end{array}$ & $\begin{array}{l}165.14 \\
00\end{array}$ & $\begin{array}{l}178.60 \\
00\end{array}$ \\
\hline
\end{tabular}

Our further modeling is inspired by the research conducted by Christensen who finds that implied volatility is better predictor of realized volatility than past realized volatility [6]. In this article we want to study only the term structure of ATM local volatility before making any predictions of realized one. 
Christensen's main point was to take non-overlapping data (calibration date + option maturity $<$ next calibration date). We have much shorter data at disposal so we didn't focus on exclusion of overlapping data. Instead for each calibration date we calculate ATM local volatility values not just for non-overlapping but for all maturities. It allows us to study the autocorrelation as overlapping effect and see if it impacts significantly the quality of our model.

Linear (3) and polynomial (4) regressions [7] are chosen as instruments to model ATM local volatility (dependent variable) w.r.t. $\mathrm{K}$ calibration dates (predictor variable) at each of $\mathrm{N}$ maturities. The model is defined as (3)

$$
\begin{gathered}
\text { LocalVol } \\
\text { LocalVol }_{T}(t)=a_{T}+b_{T} * t \\
a_{T}+b_{T} * t+c_{T} * t^{2}+d_{T} * t^{3}
\end{gathered}
$$

We verify regression assumptions using graphical analysis of distribution plots of residuals (ex. Fig.2).

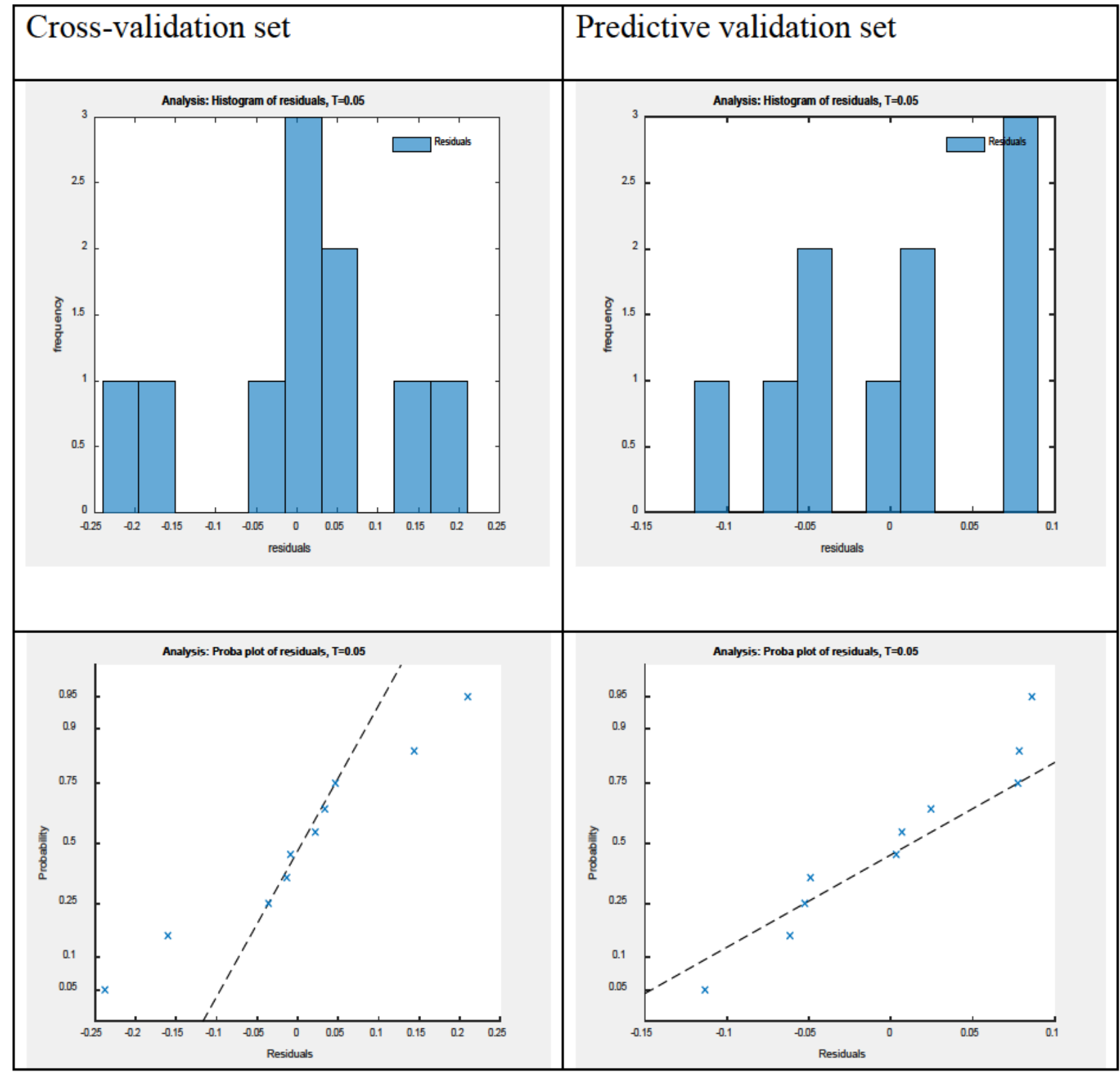

Fig. 2 ANOVA for cross-validation and predicitve sets at $T=0.05$ 
For each maturity we use such indicators as r-squared, $t$ and F-statistics, and outof-sample MSE [8] (mean squared error) (5) to evaluate the quality of regression model (Tables 3, 4, 5, 6). Durbin-Watson test is conducted to determine the presence of autocorrelation (may be caused by overlapping) in our data [9].

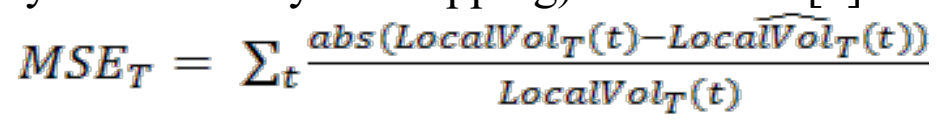

We validate simple linear and polynomial models on two different sets of calibration/validation dates. Cross validation [10] shows if the model can successfully predict ATM local volatility in intermediary OOS dates (Table 1) while predictive validation uses extrapolated OOS calibration dates (Table 2).

We do two runs on each set (basically recalibrating local volatility twice) in order to reflect on ill-posedness of Dupire optimization problem [3]: no unique solution exists. So two runs allow us to use two different inputs (local volatility matrices) to regression model and potentially obtain different results.

We use MSE and analysis of plots to measure the quality of predictions and validate obtained results. Finally we try to make some conclusions on validity and predictive ability of such models.

\section{Numerical results}

ANOVA (analysis of variance) [11] is conducted to verify the assumptions necessary to use the linear regression.

On Fig.2 we can see that residuals seem to be normally distributed for crossvalidation and prediction sets so the assumption to use the linear regression are held.

Let's take a look at numerical results obtained for the first dataset.

For cross validation set Fig.3 and Fig.4 illustrate the dynamics of calibrated ATM local volatility for the maturities $\mathrm{T}=0.05$ and $\mathrm{T}=0.4$ respectively; as well as the regression plots (modeled local volatility) that we have built ( $1^{\text {st }}$ and $3^{\text {rd }}$ order). Fig.6.

For the second (predictive validation) set we ilustrate the same data on Fig.5 and

Subplots illustrate the dymamics of underlying MSFT stock price whose peaks correspond to volatility peaks as we can see. We won't focus on this relationship as it's in the definition of Dupire model that local volatility is a function of underlying asset price.

Table 3 illustrates the statistics of the $1^{\text {st }}$ order regression model for two different calibration runs (different ATM local volatility as input) for both cross-validation and predictive sets.

Table 4 illustrates the statistics of the $3^{\text {rd }}$ order regression model for two different calibration runs (different ATM local volatility as input) for both crossvalidation and predictive sets.

\section{Graphical analysis}

As we see on the Fig. 3 and Fig.4, using $3^{\text {rd }}$ order linear regression does improve the fit. However on Fig.5, 6 we also observe that for predictive dataset it also shows very bad results on OOS validation points (huge prediction error).

Form Fig.3, 4 we observe apparent correlation between stock price jumps and local volatility jumps. By definition of Dupire's model local volatility is a function of the stock price so it's not surprising. 

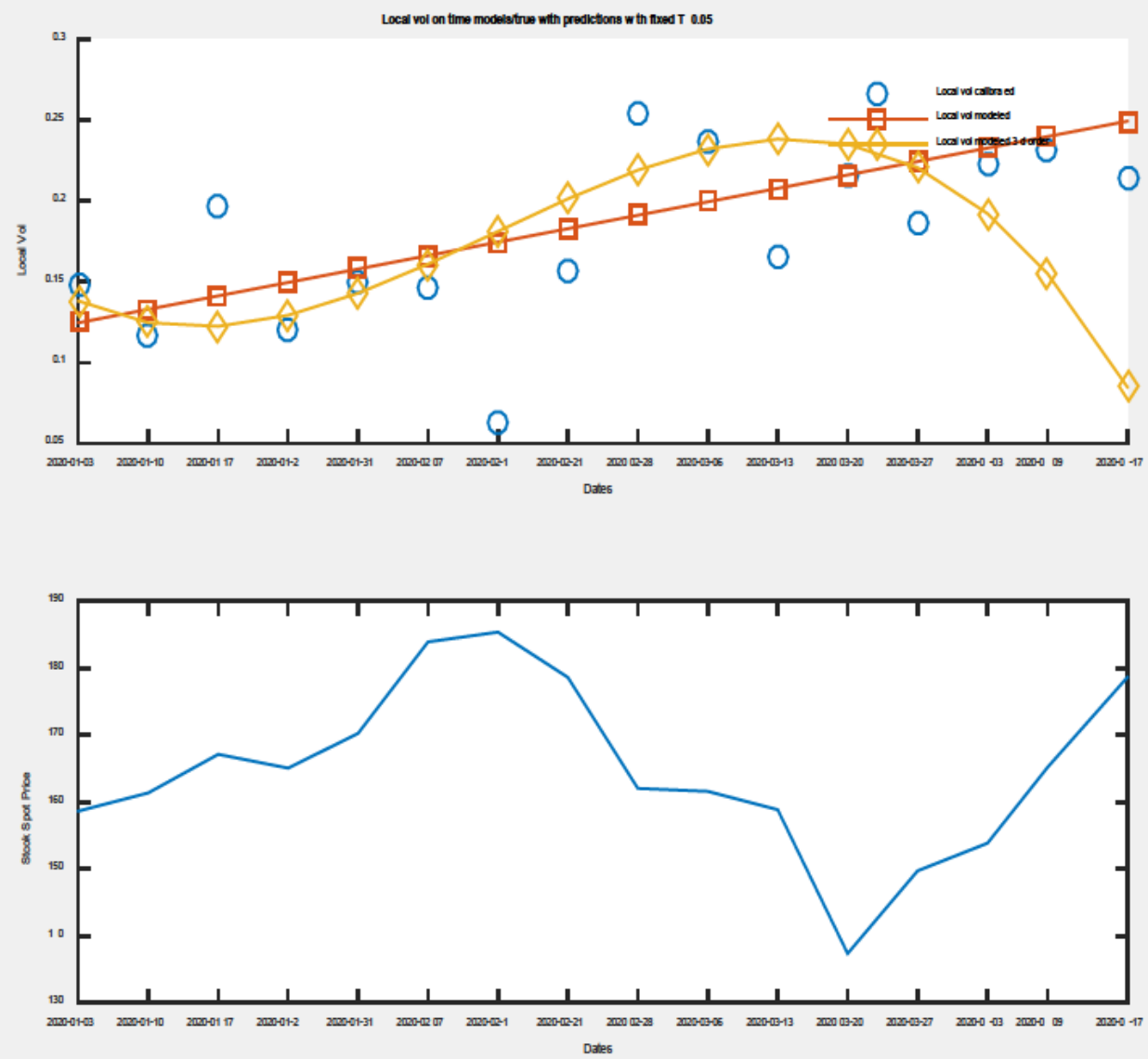

Fig. 3. Calibrated and modeled local volatility values (w.r.t. date) at $T=0,05$, Cross-Validation set
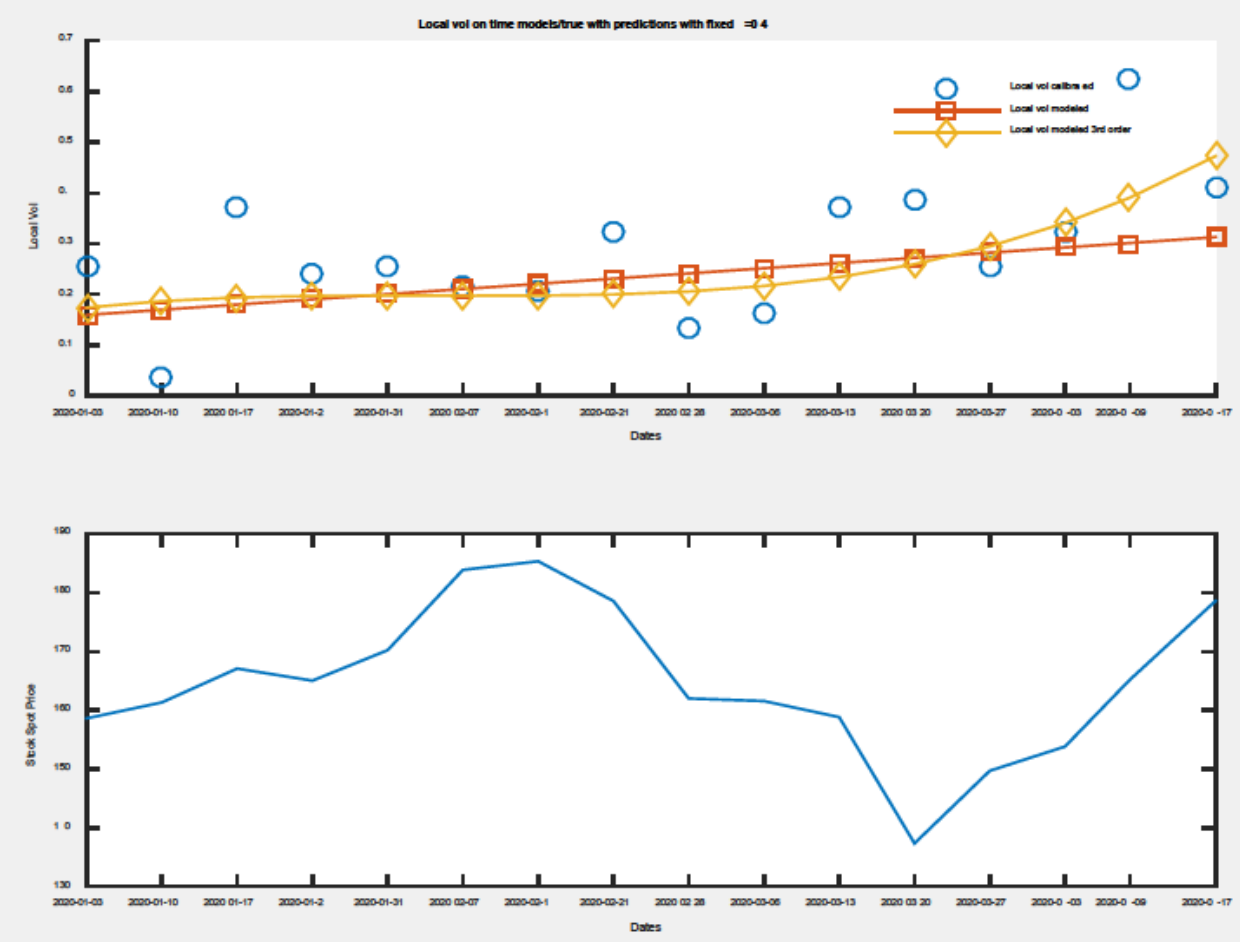

Fig.4. Calibrated and modeled local volatility values (w.r.t. date) at $\mathrm{T}=\mathbf{0 , 4}$, Cross-Validation set 

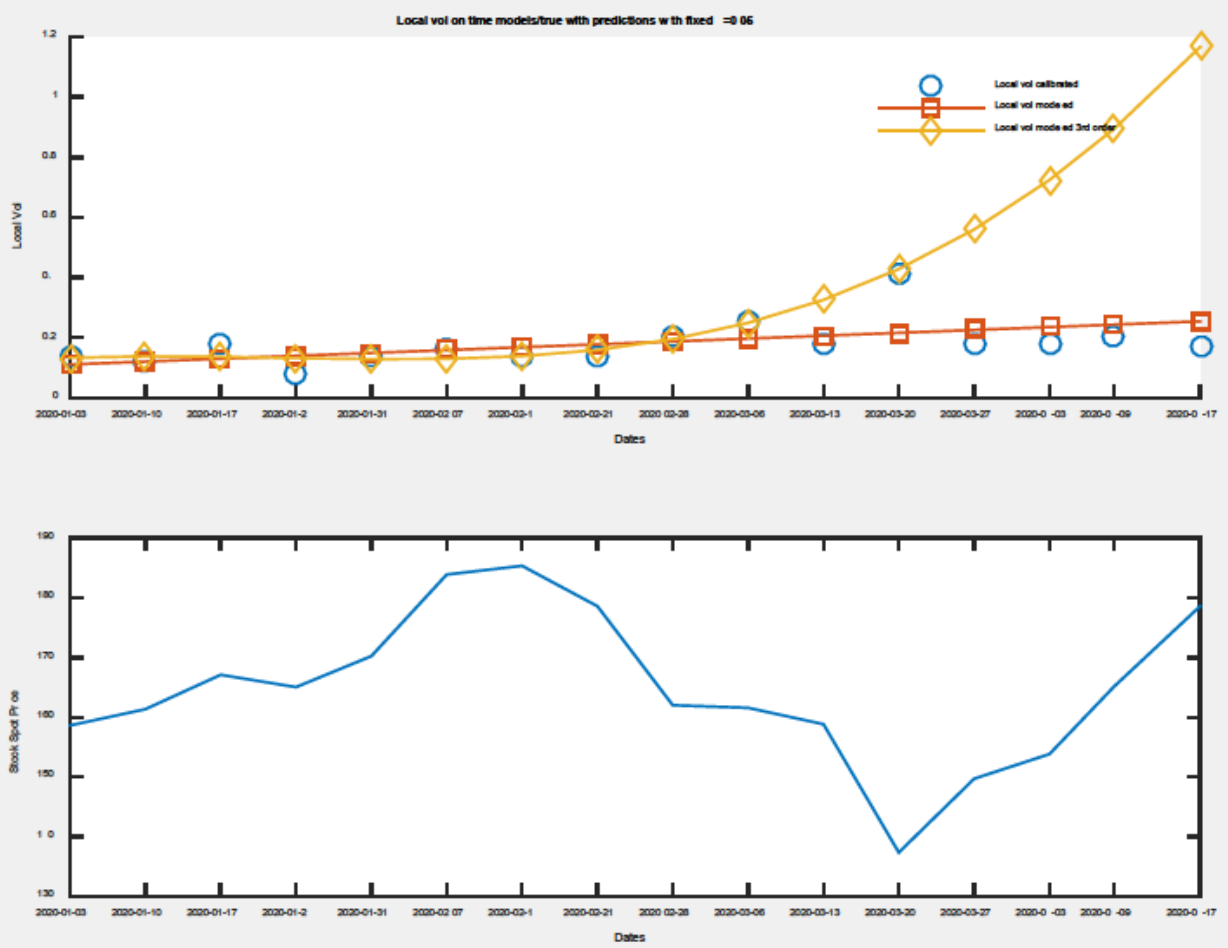

Fig.5. Calibrated and modeled local volatility values (w.r.t. date) at $\mathrm{T}=0,05$, Predictive Set
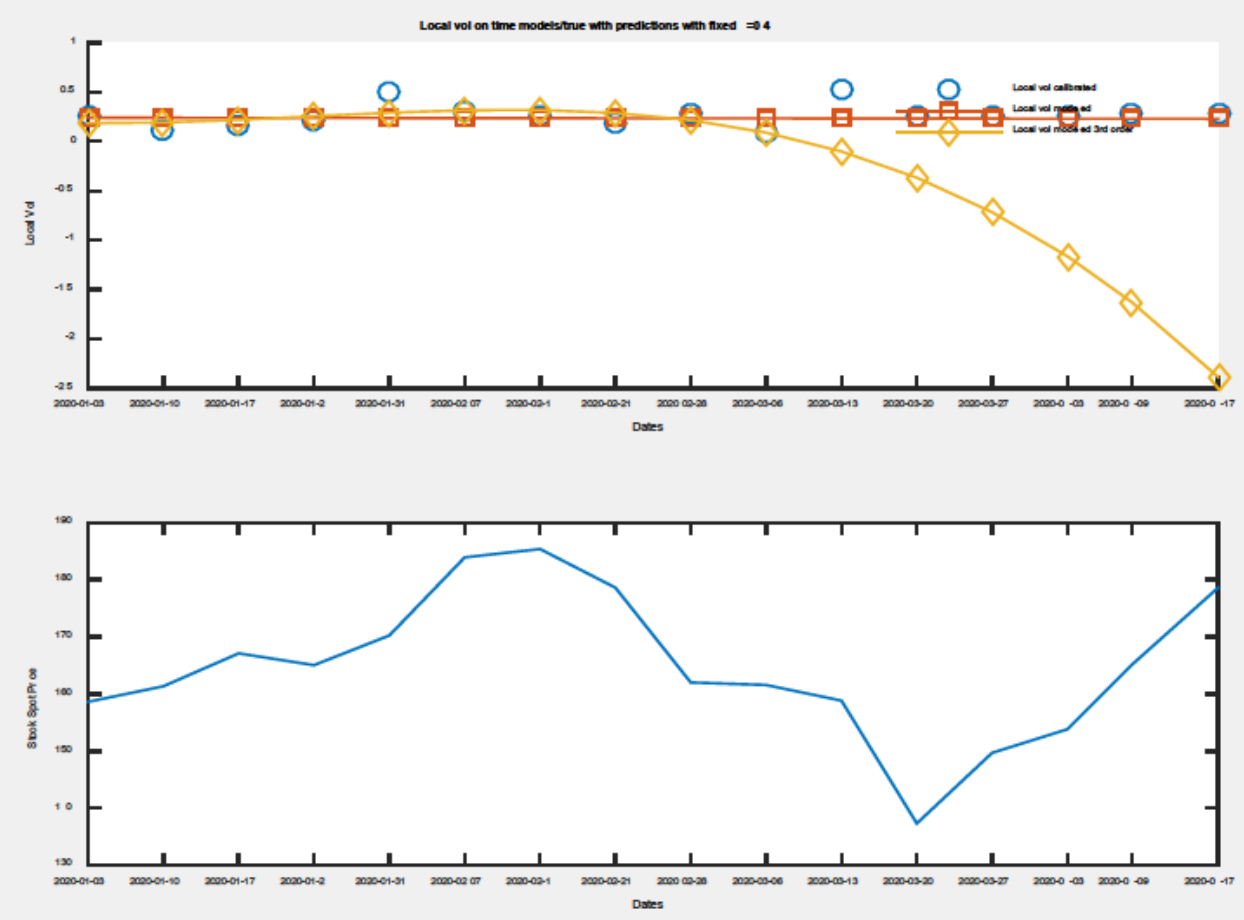

Fig.6. Calibrated and modeled local volatility values (w.r.t. date) at $\mathrm{T}=\mathbf{0 , 4}$, Predictive Set 
Table 3

Stat $1^{\text {st }}$ order linear regression, Cross-Validation and Predictive sets

\begin{tabular}{|c|c|c|c|c|c|c|c|c|}
\hline \multicolumn{9}{|c|}{ CROSS_VALIDATION SET } \\
\hline \multicolumn{9}{|c|}{ RUN 1} \\
\hline $\mathrm{T}$ & Rsq & tStat & pValue & Fstat & pValue & DW & pValue & MSE \\
\hline 0,05 & 0.0722 & 0.78892 & 0.4529 & 0.622 & 0.453 & 2.7711 & 0.5066 & 1.1020 \\
\hline 0,1 & 0.0427 & 0.5971 & 0.56695 & 0.357 & 0.567 & 2.7921 & 0.4803 & 0.8701 \\
\hline 0,15 & 0.0267 & 0.46843 & 0.65198 & 0.219 & 0.652 & 2.7533 & 0.5294 & 0.7043 \\
\hline 0,2 & 0.0169 & 0.3703 & 0.72077 & 0.137 & 0.721 & 2.6899 & 0.6133 & 0.5779 \\
\hline 0,25 & 0.0137 & 0.33354 & 0.7473 & 0.111 & 0.747 & 2.6127 & 0.7205 & 0.4858 \\
\hline 0,4 & 0.0245 & 0.44856 & 0.66565 & 0.201 & 0.666 & 2.4207 & 0.9995 & 0.3588 \\
\hline \multicolumn{9}{|c|}{ RUN 2} \\
\hline $\mathrm{T}$ & Rsq & tStat & pValue & Fstat & pValue & DW & pValue & MSE \\
\hline 0,05 & 0.0029 & 0.15303 & 0.88217 & 0.0234 & 0.882 & 2.7245 & 0.5670 & 0.7920 \\
\hline 0,1 & 0.0029 & $\begin{array}{l}- \\
0.075008\end{array}$ & 0.94205 & 0.00563 & 0.942 & 2.7164 & 0.5778 & 10.9879 \\
\hline 0,15 & 0.0027 & -0.14757 & -0.14757 & 0.0218 & 0.886 & 2.5704 & 0.7809 & 0.0565 \\
\hline 0,2 & 0.0035 & -0.16741 & -0.16741 & 0.028 & 0.871 & 2.4130 & 0.9894 & 1.3127 \\
\hline 0,25 & 0.0014 & -0.10563 & 0.91847 & 0.0112 & 0.918 & 2.2683 & 0.7811 & 5.4034 \\
\hline 0,4 & 0.0282 & 0.48174 & 0.64289 & 0.232 & 0.643 & 1.7931 & 0.2489 & 0.0615 \\
\hline \multicolumn{9}{|c|}{ PREDICTIVE SET } \\
\hline \multicolumn{9}{|c|}{ RUN 1} \\
\hline $\mathrm{T}$ & Rsq & tStat & pValue & Fstat & pValue & DW & pValue & MSE \\
\hline 0,05 & 0,0665 & 0,7550 & 0,4718 & 0,57 & 0,472 & 2,1683 & 0,6536 & 1.62185 \\
\hline 0,1 & 0,0246 & 0,44937 & 0,6650 & 0,202 & 0,665 & 1,8612 & 0,3129 & 1.77455 \\
\hline 0,15 & 0,00771 & 0,2493 & 0,8094 & 0,0622 & 0,809 & 1,76 & 0,2312 & 1.597367 \\
\hline 0,2 & 0,00289 & 0,1522 & 0,88276 & 0,232 & 0,883 & 1,7166 & 0,2005 & 1.010617 \\
\hline 0,25 & 0,00175 & 0,1185 & 0,9085 & 0,014 & 0,909 & 1,6910 & 0,1839 & 0.7554 \\
\hline 0,4 & 0,00901 & 0,26973 & 0,7941 & 0,0728 & 0,794 & 1,4869 & 0,0835 & 0.591483 \\
\hline \multicolumn{9}{|c|}{ RUN 2} \\
\hline $\mathrm{T}$ & Rsq & tStat & pValue & Fstat & pValue & DW & pValue & MSE \\
\hline 0,05 & 0.2387 & 1.5838 & 0.1519 & 2.51 & 0.152 & 2.2346 & 0.7426 & 0.3800 \\
\hline 0,1 & 0.0700 & 0.77576 & 0.46021 & 0.602 & 0.46 & 2.2862 & 0.8146 & 0.3609 \\
\hline 0,15 & 0.0013 & 0.10064 & 0.92231 & 0.0101 & 0.922 & 2.1830 & 0.6730 & 0.4178 \\
\hline 0,2 & 0.0107 & -0.29444 & 0.77592 & 0.0867 & 0.776 & 2.1200 & 0.5917 & 0.5505 \\
\hline 0,25 & 0.0296 & -0.49384 & 0.63469 & 0.244 & 0.635 & 2.0818 & 0.5448 & 0.6236 \\
\hline 0,4 & 0.0441 & -0.60744 & 0.5604 & 0.369 & 0.56 & 2.1609 & 0.6439 & 0.5586 \\
\hline
\end{tabular}


Table 4

Stat $3^{\text {rd }}$ order linear regression, Cross-Validation and Predictive sets

CROSS VALIDATION SET

RUN 1

\begin{tabular}{|l|l|l|l|l|l|l|}
\hline T & Rsq & Fstat & $\begin{array}{l}\text { pValu } \\
\text { e }\end{array}$ & DW & pValue & MSE \\
\hline 0,05 & 0.3466 & 1.06 & 0.433 & 3.3249 & 0.2643 & 2.2290 \\
\hline 0,1 & 0.2532 & 0.678 & 0.597 & 3.1504 & 0.5084 & 1.6553 \\
\hline 0,15 & 0.1980 & 0.494 & 0.7 & 3.0213 & 0.7299 & 1.2441 \\
\hline 0,2 & 0.1698 & 0.409 & 0.752 & 2.9279 & 0.8984 & 0.9266 \\
\hline 0,25 & 0.1646 & 0.394 & 0.762 & 2.8588 & 0.9765 & 0.6804 \\
\hline 0,4 & 0.2150 & 0.548 & 0.668 & 2.7809 & 0.8385 & 0.3412 \\
\hline RUN 2 \\
\hline \multicolumn{7}{|l|}{} \\
T & Rsq & Fstat & \multicolumn{1}{l|}{ pValu } & DW & pValue & MSE \\
\hline 0,05 & 0.1451 & 0.339 & 0.798 & 3.0525 & 0.5670 & 1.0515 \\
\hline 0,1 & 0.2543 & 0.682 & 0.682 & 3.3958 & 0.1882 & 11.4535 \\
\hline 0,15 & 0.3394 & 1.03 & 0.445 & 3.5080 & 0.0953 & 0.1000 \\
\hline 0,2 & 0.3967 & 1.31 & 0.354 & 3.5053 & 0.0971 & 1.0687 \\
\hline 0,25 & 0.4308 & 1.51 & 0.304 & 3.4415 & 0.1463 & 3.3493 \\
\hline 0,4 & 0.5279 & 2.24 & 0.185 & 3.0253 & 0.7228 & 0.0480 \\
\hline PRDI
\end{tabular}

\section{PREDICTIVE SET}

RUN 1

\begin{tabular}{|l|l|l|l|l|l|l}
\hline $\mathrm{T}$ & Rsq & Fstat & $\begin{array}{l}\text { pValu } \\
\mathrm{e}\end{array}$ & DW & pValue & MSE \\
\hline 0,05 & 0,101 & 0,225 & 0,876 & 2,2940 & 0,2854 & 1.447833 \\
\hline 0,1 & 0,0758 & 0,164 & 0,917 & 1,9728 & 0,0720 & 0.914233 \\
\hline 0,15 & 0,0801 & 0,174 & 0,91 & 1,86 & 0,0380 & 1.156333 \\
\hline 0,2 & 0,0986 & 0,219 & 0,881 & 1,8387 & 0,0314 & 0.930917 \\
\hline 0,25 & 0,113 & 0,254 & 0,856 & 1,8260 & 0,0287 & 0.753033 \\
\hline 0,4 & 0,192 & 0,476 & 0,71 & 1,7416 & 0,0146 & 0.487983 \\
\hline
\end{tabular}

RUN 2

\begin{tabular}{|l|l|l|l|l|l|l|}
\hline $\mathrm{T}$ & Rsq & Fstat & $\begin{array}{l}\text { pValu } \\
\text { e }\end{array}$ & DW & pValue & MSE \\
\hline 0,05 & 0.3741 & 1.2 & 0.388 & 2.6956 & 0.7426 & 2.6968 \\
\hline 0,1 & 0.4477 & 1.62 & 0.281 & 3.1316 & 0.4939 & 4.2388 \\
\hline 0,15 & 0.4814 & 1.86 & 0.238 & 2.9443 & 0.7971 & 5.5686 \\
\hline 0,2 & 0.4887 & 1.91 & 0.229 & 2.6847 & 0.7713 & 6.6982 \\
\hline 0,25 & 0.4928 & 1.94 & 0.224 & 2.5788 & 0.6151 & 7.6306 \\
\hline 0,4 & 0.5155 & 2.13 & 0.198 & 2.9325 & 0.8170 & 7.2618 \\
\hline
\end{tabular}


ANOVA graphs on Fig.2 demonstrate that the assumptions are held and residuals seem to be normally distributed so linear regression can be used to model the relationship.

\section{Let's now analyze R-squared}

In terms of r-squared we can state form Tables 3, 4 that $1^{\text {st }}$ order regression has very low fit and is unable to fit well the data. We can justify it by volatile character of the data as we studies crisis period from January 2020 to April 2020.

However the $3^{\text {rd }}$ order regression fits the data much better in terms of r-squared for both datasets. Volatile character of the data in the crisis period justifies using $3^{\text {rd }}$ order model to fit the data.

Good fit does not imply good predictive ability so we study regression statistics to see the significance of such model. We also validate it on OOS data points.

\section{Let's now analyze $T$-statistics}

Null hypothesis designs the absence of linear relationship between calibration dates and local volatility.

pValue is a probability to observe T-statistics as extreme or more extreme than the one under null hypothesis which is equivalent to approval of null hypothesis. So lower $\mathrm{pValue}$ means that there are more chances to reject null hypothesis and more chances that there is a linear relationship between the independent and the dependent variable.

We reject null hypothesis if $\mathrm{pValue}$ is lower than significance level we choose (5\% in our case).

Looking at Table 3 we state with $95 \%$ probability that calibration date has no linear relationship with local volatility so it does not make sense to include it into the model for given sample. It is the case for all maturities for both runs for both datasets. The calibration date is not a significant predictor for local volatility in $1^{\text {st }}$ order linear model.

\section{Let's analyze F-statistics}

F-statistics shows whereas the whole model is better than intercept-only model (simple mean). Let's take a look at F-statistics in the Table 3 and Table 4. Choosing $5 \%$ significance level we can conclude that neither $1^{\text {st }}$ nor $3^{\text {rd }}$ order linear regression model can outperform simple mean. So both of them are overall insignificants. It holds for both datasets.

\section{Let's analyze auto-correlation Durbin-Watson criteria:}

Null hypothesis is absence of autocorrelation between residuals.

Significantly low pValue means that we can reject null hypothesis and state autocorrelation. We use level of significance at $5 \%$.

Looking at Table 3 we state that $p$ Value is quite large for all maturities. So we conclude that no autocorrelation is present for $1^{\text {st }}$ order regressions for crossvalidation dataset.

Looking at Table 4 we state that pValue is quite large for all maturities. For the RUN1 in Predictive dataset however we have lower pValues that can pass the level of significance of $5 \%$ for $3^{\text {rd }}$ order model. So we conclude that there can be an autocorrelation of residuals for $3^{\text {rd }}$ order model for some runs. However as the whole model is not efficient nor significant we are not interested in getting rid of this 


\section{phenomena.}

We could also suggest that there is no autocorrelation in general case as the data has quite little or no overlapping nature as for calibration we used MSFT options with quite short maturities.

\section{Out-of-the-sample MSE analysis}

We can also see it in MSE measure on out-of-the-sample points:

In Table 3 we observe that for $1^{\text {st }}$ order regression models out-of-sample MSE is quite far from 0 which means we cannot use these models to predict local volatility at validation dates. This holds for both datasets.

In Table 4 we also observe that for $3^{\text {rd }}$ order regression models out-of-sample MSE is quite far from 0 which means we cannot use these models to predict local volatility at validation dates. This holds also for both datasets.

\section{Conclusions}

In current work we calibrated local volatility from two different datasets and two different runs. Therefore we could perfectly observe the multiplicity of solutions of Dupire calibration problem implied by ill-posedness of the problem. We observe this multiplicity rather than try to eliminate it.

Firstly by conducting graphical analysis we observe that for both runs and both datasets there is an apparent correlation between stock price jumps and local volatility jumps. It's normal as functional relation is implied by Dupire's model.

Secondly by analyzing ANOVA graphs we can state that the assumptions are held and residuals seem to be normally distributed so linear regression can be used to model the time-series of local volatility.

Thirdly we conclude that $3^{\text {rd }}$ order regression model fits the data much better in terms or r-squared than $1^{\text {st }}$ order one. Volatile character of the data in the crisis period justifies using $3^{\text {rd }}$ order model to fit the data.

Fourthly by analyzing t- and F-statistics for both $1^{\text {st }}$ and $3^{\text {rd }}$ regression models we conclude that calibration date has no linear relationship with local volatility so it does not make sense to include it as factor into the model. Both models are overall insignificant.

Fifthly we analyze autocorrelation of residuals for both models using DurbinWatson test. We conclude that in general there is no autocorrelation despite it is present in some runs for some maturities. The absence of autocorrelation can be explained by little or no overlapping nature of observations as we use quite short maturities.

Finally despite statistical insignificance of our regression models we study their predictive ability by analyzing MSE measure on out-of-sample data points. For both models and datasets we conclude that we cannot use calibration date as predictor for local volatility. We will lean on this conclusion in our further research to exclude calibration date from the list of volatility predictors.

\section{References}

1. Dupire, B.: Pricing with a smile. Risk, 7(1), 18-20 (1994)

2. Black, Fisher S.; Scholes, Myron S.: The Pricing of Options and Corporate Liabilities, Journal of Political Economy, 81(3), 637-654 (1973) 
3. Ben Hamida, S., Cont, R.: Recovering volatility from option prices by evolutionary optimization. Journal of computational finance, 8(4), 18-33 (2020). http://dx.doi.org/10.21314/JCF.2005.130

4. Bondarenko, M., Bondarenko, V.: On dynamics of at-the-money local volatility calibrated from time series of VIX option. Modern engineering and innovative technologies, 12(6), 1-20 (2018). http://dx.doi.org/10.21511/nfmte.7.2018.01

5. Cerf, R.: Asymptotic convergence of genetic algorithms. Advances in Applied Probability, 30(2), 521-550 (1998). https://doi.org/10.1239/aap/1035228082

6. Christensen, B.J., Prabhala, N.R.: The relation between implied and realized volatility, Journal of Financial Economics, 50, 125-150 (1998).

7. Chatterjee, S. and Hadi, A.S.: Regression Analysis By Example, 5th ed., John Wiley and Sons, New York, 2012.

8. Rouaud, M.: Probability, Statistics and Estimation.

http://www.incertitudes.fr/book.pdf Accessed 3 February 2021.

9. Durbin, J.; Watson, G. S.: Testing for Serial Correlation in Least Squares Regression, I. Biometrika. 37 (3-4): 409-428 (1950). doi:10.1093/biomet/37.3-4.409

10. Berrar, D.: Cross-validation, Reference Module in Life Sciences, 2018. DOI: 10.1016/B978-0-12-809633-8.20349-X

11. Fisher, R.: The Correlation Between Relatives on the Supposition of Mendelian Inheritance, Philosophical Transactions of the Royal Society of Edinburgh, 52, 399-433 (1918).

The article has been sent 21.03.2021 